\title{
Arquitetura inclusiva: a planta tátil como instrumento de projeto colaborativo com portadores de deficiência visual
}

Inclusive architecture: the tactile model as collaborative design tool with the blind and visually impaired people

\author{
MUSSI, Andréa Quadrado \\ PPGARQ-IMED - Programa de Pós-Graduação em \\ Arquitetura e Urbanismo da Faculdade Meridional, \\ Brasil \\ andrea@imed.edu.br
}

ROMANINI, Anicoli

IMED- Faculdade Meridional, Brasil

anicoli@imed.edu.br

\author{
LANTELME, Elvira \\ IMED- Faculdade Meridional, Brasil \\ Elvira.lantelme@imed.edu.br
}

MARTINS, Marcele Salles
IMED- Faculdade Meridional, Brasil
marcelemartins@imed.edu.br

\begin{abstract}
This work aims to analyze the use of tactile model as a way to provide a collaborative medium between the blind and visually impaired people and architects in order to enable the development of the architectural project of a center for training and rehabilitation in the city of Passo Fundo, RS, Brazil. Therefore, two tactile models have been built with different materials and technologies and tested by blind and visually impaired people. This paper describes the process of building the models, their strengths and weaknesses and discusses their applicability to the development of the rehabilitation center design project.
\end{abstract}

Keywords: Blind and visually impaired people, Design process, Tactile model, Cutter laser.

\section{Introdução}

De acordo com os dados da Organização Mundial de Saúde (OMS, 2014), 285 milhões de pessoas apresentam deficiência visual em todo o mundo, sendo 39 milhões totalmente cegas e 246 milhões com baixa visão. No estado do Rio Grande do Sul, Brasil, o Censo Demográfico do IBGE (2010), demonstra que, de uma população total de 10.693.929 habitantes, 28.748 habitantes possuem cegueira total, 323.137 possuem baixa visão e ainda, 1.548.749 pessoas tem algum tipo de dificuldade visual. Especificamente, no município de Passo Fundo, local de realização da pesquisa, com um total de 184.826 habitantes, 529 pessoas são cegas, 5.184 apresentam grande dificuldade e 25.247 habitantes têm alguma dificuldade visual.

A OMS (2014) estima, ainda, que $90 \%$ dos deficientes visuais em todo o mundo vivem em sub-condições, seja por estarem em situação de extrema pobreza e/ou não possuírem seus direitos assegurados, a partir do princípio da isonomia que determina que toda pessoa possui livre-arbítrio, independência e autonomia. Este princípio é inclusive abordado na Lei Brasileira 7.853, de 24/10/1989, que dispõe sobre 0 apoio às pessoas com alguma deficiência e sua integração social, obrigando a inclusão de questões específicas sobre a parcela da população que possui deficiência.

A maioria das pessoas com algum tipo de incapacidade visual possui enormes dificuldades de sobreviver cotidianamente, realizar-se pessoal e profissionalmente, adentrar na vida comunitária, no sistema escolar, no mercado de trabalho e gerar renda própria. Conhecendo o impacto que este fato causa nas pessoas e na sociedade, bem como dos obstáculos físicos e financeiros que estas enfrentam diariamente, é dever das instituições de atendimento aos portadores de deficiência visual (PDVs) eliminar ou reduzir ao máximo estes obstáculos, com o oferecimento de serviços que invistam nestas pessoas, através de sua formação e capacitação, despertando o potencial que apresentam para superar estes obstáculos.

Além disso, constata-se que um dos motivos da produção da exclusão é decorrente da falta de conhecimento sobre as pessoas com deficiência. Assim, cabe às instituições envolvidas com a causa das pessoas com deficiência educar a sociedade a conviver com as diferenças, inerente a todo ser humano.

Este contexto de desconhecimento perpassa pelo processo projetual do arquiteto baseado quase que exclusivamente na visão, tanto na concepção como na representação e comunicação do mesmo. Assim como, no entendimento que os profissionais manifestam em seus projetos quanto a exploração em sua plenitude das qualidades espaciais que os ambientes podem possuir, em especial, aquelas não relacionadas com a visão diretamente (Heylighen; Herssens, 2014).

Esta pesquisa tem por objetivo analisar o uso de plantas táteis como forma de proporcionar um meio de colaboração entre os deficientes visuais e arquitetos a fim de possibilitar 0 desenvolvimento do projeto arquitetônico de um centro de habilitação e reabilitação de deficientes visuais na cidade de Passo Fundo/RS. 


\section{Arquitetura Inclusiva e o proceso projetual}

A sociedade se desenvolve quando acha mecanismos (métodos e técnicas) que inclua todos os grupos de indivíduos que a compõe, muitos destes antes excluídos, que é o caso dos PDVs, constituído tanto pelas pessoas cegas como as de baixa visão (SILVA; SILVA, 2013).

A avaliação da imagem surge da pessoa e do ambiente e da interação mais ampla entre os dois. Isto talvez varie com aspectos biológicos, personalidade, experiência sociocultural, níveis de adaptação, acertos, expectativas e fatores internos e externos (NASAR, 1998). $\mathrm{Na}$ avaliação do espaço, que possui muitos atributos, estão envolvidos 0 ambiente perceptivo (que envolve sentimentos relacionados a estrutura da forma) e o ambiente cognitivo (que requer atividade mental, de reconhecer o conteúdo de um determinado lugar, definir inferências sobre este lugar e avaliar isto). Se filtra a resposta avaliativa ao se interromper a lente da percepção e cognição do ambiente (NASAR, 1998). Sendo assim, a percepção é o processo de obtenção ou entrada, recepção de dados e a cognição é a função de entrada que envolve os processos de opinião, recordações, sensações, é influenciada pela personalidade, grupo social e cultura (LANG, 1974).

A aquisição de informações do ambiente realizada pelo PDV difere principalmente no processo de percepção, o qual utiliza a relação, quase que conjunta, dos outros sentidos. Caiado (2002) ao analisar artigos sobre concepções de aprendizagem e ensino a pessoas com cegueira identificou que a maioria dos autores considera que as pessoas cegas conhecem o mundo a partir dos sentidos sensoriais remanescentes e os autores destacam a importância do estímulo sensorial na educação dos mesmos.

Quando as pessoas podem se mover e orientar-se no ambiente de forma segura e autônoma, eles estão mais propensos a ter uma sensação de segurança e independência, dois elementos essenciais para a sua integração em uma sociedade complexa (ESPINOSA et al., 1998).

Os centros de habilitação e reabilitação desempenham um papel relevante na inclusão dos PDVs e no treinamento para a locomoção autônoma nos ambientes. Geralmente as associações sem fins lucrativos gerenciam estes centros. Em Passo Fundo, a Associação Passofundense de Cegos (APACE) é referência na região no atendimento dos PDVs. Localizada numa cidade-pólo constituída por mais de 130 municípios em sua área de abrangência. Destaca-se pela representatividade na área médica, cultural e tecnológica sendo referência na área da saúde por possuir um dos mais modernos centros médicos do sul do país. Por ter a cidade como referência, as pessoas com deficiência visual procuram a sede da APACE para atendimentos que possam suprir suas necessidades de habilitação e reabilitação no sentido de conquistarem acessibilidade plena e autonomia, bem como sua inclusão social.

A APACE possui como meta a educação, a reabilitação e, sobretudo, a promoção da independência e a garantia dos direitos civis, políticos e sociais por meio dos serviços oferecidos à comunidade de deficientes visuais. Assim, para atender o grande contingente de pessoas cegas da cidade de Passo Fundo e região se justifica a necessidade de criar uma estrutura física adequada com profissionais especializados e capacitados para atender a todas as demandas decorrentes da necessidade de cada indivíduo com deficiência visual, visto que cada um apresenta situações diferentes e bem específicas.

Embora, a APACE esteja localizada em um ambiente provisório e com poucos profissionais, a instituição, por meio de suas atividades, oferece um suporte técnico especializado adequado às necessidades individuais e coletivas das pessoas com deficiência visual que procuram a instituição, e assim tem sido agente de transformação e de inclusão social, o que se manifesta no aumento de crianças com deficiência visual incluídas nas escolas do ensino regular.

É necessário conhecer a realidade dos PDVs que utilizam um centro de habilitação e reabilitação, por meio de projetos personalizados às suas demandas, que seja efetivamente inclusivo e considere a expertise dos PDVs quanto a percepção das qualidades espaciais não visuais e muitas vezes apercebidas pelos projetistas.

Heylighen e Herssens (2014) apontam que o processo projetual do arquiteto desconsidera as sensações, além daquelas estimuladas pela visão, que o espaço modificado exerce sobre as pessoas, tanto no projeto em si, como na representação do mesmo. A comunicação dos projetos ocorre por meio de desenhos que expressam algumas qualidades, no máximo, de conforto ambiental, estando centradas nas experiências visuais, excluindo o resto do corpo humano de experimentar totalmente o projeto, porém a experiência que as pessoas têm do ambiente construído é multissensorial. Os PDVs podem esclarecer, como expertises no assunto, como sentem o espaço que vivenciam. Uma vez entendido este processo, pode ser agregado valor para a prática projetual, a fim dos projetos serem mais abrangentes, conferindo ambientes mais genuínos ao transparecerem às pessoas as suas características multissensoriais. O entendimento de como os PDVs se usufruem dos espaços pode despertar o arquiteto para a percepção de qualidades espaciais não exploradas ou insuficientemente abordadas nos projetos, como as qualidades não visuais, tais como cheiro, som ou qualidade do ar.

Os projetos colaborativos, vão além da transcrição do espaço para a pessoa portadora de deficiência visual, permitem uma maior interação com os projetistas e contribuição na construção mais assertiva do projeto frente as necessidades reais demandadas pelos próprios futuros usuários. 
Os recursos de representação do espaço, como plantas, mapas e maquetes táteis vem aumentando no cotidiano dos PDVs, porém é imprescindível levar em consideração, como destaca Silva e Silva (2013) que "para a interpretação das informações contidas no mapa e a mobilidade no ambiente, o portador de deficiência visual apresenta uma estrutura diferente do vidente, no contexto de aquisição de informações". Ao mesmo tempo, Milan (2008) menciona que a "eficiência da maquete tátil na orientação de deficientes visuais depende também da capacidade de raciocínio espacial desses usuários, e não apenas da qualidade do modelo".

A planta tátil é a peça que representa, de modo vertical, elementos arquitetônicos como cheios e vazios, formas e espaços, proporções e aberturas (SPERLING; VANDIER; SCHEEREN, 2015). A planta tátil atua pedagogicamente no entendimento do espaço vivenciado diariamente e pode promover uma percepção antecipada daquele espaço a ser vivenciado, contribuindo para uma maior eficácia no usufruto das edificações (MILAN, 2008; BEM; PUPO, 2015; SPERLING; VANDIER; SCHEEREN, 2015).

Caiado (2002) menciona que há duas concepções dentre as abordagens de aprendizagem e ensino das pessoas com cegueira: estimulação sensorial como treino sensorial e estimulação sensorial como exploração sensorial. A planta tátil estimula os sentidos e permite que a pessoa com deficiência visual explore o ambiente e tenha um domínio do mesmo antecipando as percepções quando da exploração propriamente dita do espaço a circular. Pode atuar como mecanismo pedagógico de compreensão do espaço circundante, sendo a planta tátil um estímulo sensorial como treino sensorial e ao percorrer o ambiente em si possibilitaria a estimulação sensorial como exploração sensorial, no momento que a pessoa com deficiência visual terá contato direto com o objeto a perceber.

Os mapas táteis são mais eficientes no deslocamento dos PDVs no ambiente urbano quando comparado aos métodos de interação direta com o ambiente ou descrição verbal e orientada do mesmo (Espinosa, et al., 1998).

As maquetes táteis elaboradas de ambientes internos possuem a característica de possuírem o mobiliário, o que contribui para a compreensão do deslocamento dentro do espaço pelo PDV.

Bem e Pupo (2015) perceberam na revisão de diversos materiais bibliográficos acerca de técnicas de prototipagem rápida usadas para confecção de mapas e maquetes táteis para PDV, que a interpretação através do tato aumenta com a utilização de volumes em comparação aos mapas convencionais de representação tátil, ajudando na criação do mapa mental.

Faria e Elali (2012) realizaram projeto arquitetônico habitacional em conjunto com usuário com deficiência visual utilizando maquete tátil artesanal, obtendo grande êxito na participação. Acrescentam ainda que não utilizaram tecnologias digitais de alta performance na confecção das maquetes táteis, pelo fato de serem pouco acessíveis.
Por outro lado, Bem e Pupo (2015) enfatizam a facilidade de reprodução das representações táteis oriundas de prototipagem rápida considerando que os arquivos estariam prontos para serem copiados e ainda apontam as características do emprego desta tecnologia: "possibilidade de representação com grande resolução das texturas, símbolos e texto em braile, facilitando a sua leitura, além da resistência do produto à dinâmica associada à sua leitura". Sperling et al. (2015) menciona que a cortadora a laser possibilita a confecção de plantas táteis com pouca variedade de textura e materiais, porém permite exatidão dimensional, importante para uma leitura mais apurada pelo portador de deficiência visual (PDV).

Portanto o ganho de desempenho com o uso de tecnologias de prototipagem rápida nas representações táteis dos ambientes justificaria o emprego

\section{Método}

O trabalho de pesquisa foi realizado em colaboração com a APACE, localizada na cidade de Passo Fundo, RS, Brasil. Reconhecendo a importância da atuação da APACE na capacitação e reabilitação de pessoas com deficiências visuais, a Prefeitura Municipal de Passo doou à instituição um terreno no qual a APACE pretende construir um centro de habilitação e reabilitação para atender as suas necessidades.

O meio para realizar um projeto colaborativo entre os pesquisadores e as pessoas com deficiência visual foi a elaboração de uma planta tátil da APACE, a fim de estudar a percepção e estimular a participação dos mesmos no entendimento dos espaços.

Nesta pesquisa foram desenvolvidos dois tipos de plantas táteis (Figura 1) para o mesmo espaço da APACE, a fim de elencar qual seria a mais adequada para aplicar ao grupo de entrevistados selecionados da pesquisa e que servirá como comparativo para a realização do projeto colaborativo da nova sede.

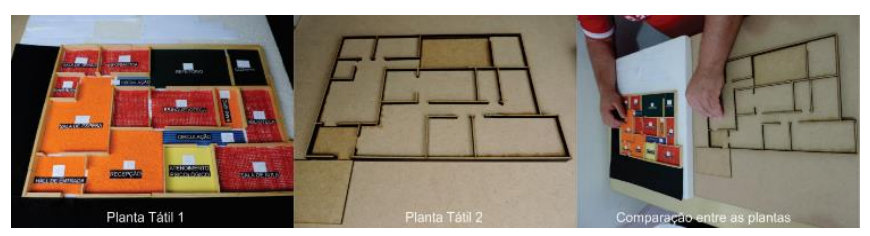

Figura 1: Plantas táteis 1 e 2 e usuário referência as comparando.

O material da primeira planta tátil (planta tátil 1) testada com o usuário referência foi base de isopor, paredes em madeira e pisos com texturas, sendo a técnica manual nos cortes e montagem. A planta tátil 1 continha números em braile em cada um dos ambientes e uma legenda com o nome respectivo de cada compartimento. Enquanto que na planta tátil feita na cortadora a laser (planta tátil 2) foi utilizado MDF em todas as partes e a técnica permitiu cortes mais precisos e homogêneos sem remendas, permitindo também mais detalhes de saliências nas paredes, por exemplo. Nesta segunda planta não foi colocado legenda. 
Para a realização do teste foi definido um usuário referência, uma pessoa que se desloca tanto em espaços externos como internos de maneira independente e que foi comprovado que possui capacidade adequada de raciocínio espacial. Assim foi feita uma comparação das percepções sentidas pelo usuário referência (pessoa portadora de deficiência visual, presidente da APACE) para cada uma das técnicas e materiais utilizados em cada planta tátil.

A planta tátil 2 foi validada pelo usuário referência, que não é deficiente visual desde a nascença, adquirindo a cegueira total depois. A indicação para a seleção dos participantes da pesquisa é que possuam características de reconhecimento do espaço e de mobilidade semelhantes ao usuário referência, a fim de poderem contribuir com o objetivo da pesquisa. Com isso esta planta em conjunto com um questionário foi aplicada para mais 10 (dez) usuários cegos e com baixa visão. 0 questionário, continha questões socioeconômicas na parte inicial e questões específicas sobre a percepção da planta tátil.

Os testes foram feitos na sede da APACE, gravados e filmados.

\section{Resultados e Discussão}

A capacidade de raciocínio espacial do PDV realmente é importante para a compreensão da planta tátil. Esta comprovação se deu no momento em que a planta tátil foi apresentada ao usuário referência, sem mencionar de qual edificação se tratava, e em seguida que tateou a planta conseguiu identificar que se tratava da APACE, ao mesmo tempo, conseguiu identificar todos os espaços com a máxima precisão, sem errar nenhum deles, inclusive conseguiu perceber quais são os espaços maiores e menores.

$\mathrm{Na}$ primeira planta tátil o usuário referência iniciou pela identificação das legendas em braile do zoneamento por setor, seguida pela leitura das legendas numeradas que identificavam o nome de cada compartimento. Após passou para a planta, a partir da identificação da entrada, iniciou o percurso e relatou os espaços. Identificou as texturas, como sendo diferentes tipos de piso, pois o local possui piso de madeira e cerâmico, contrária a intenção dos pesquisadores com a diferenciação das texturas, para identificar o zoneamento por setor.

$\mathrm{Na}$ comparação entre as duas plantas táteis, o usuário referência citou que a planta tátil feita na cortadora a laser é mais limpa e nítida que a artesanal. Isto é devido principalmente ao material e a técnica utilizada em cada uma das plantas táteis (Figura 2).

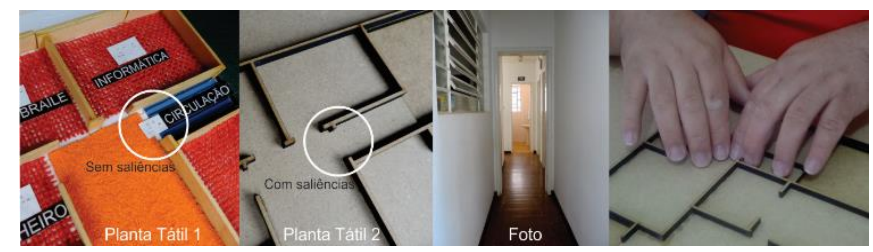

Figura 2: Foto dos marcos da porta no corredor e representação na planta tátil 2 e sem esta representação na planta tátil 1.
A planta tátil 2 tem precisão nas dimensões, é mais bem acabada, segura ao toque e possui maior durabilidade, característica necessária para ter maior usabilidade, favorecendo manuseios repetitivos e transporte. Portanto a planta tátil 2 foi mais facilmente percebida, mesmo apesar desta não conter legendas e nenhuma outra indicação escrita em braile.

Na planta tátil feita na cortadora a laser foram acrescidos os desníveis entre os ambientes (Figura 3 e 4), o que foi muito percebido e elogiado pelo colaborador da pesquisa (Figura 5), pela sua percepção os desníveis são muito importantes, bem como, foram colocadas as diferenças de saliências e marcos de vãos (Figura 2), que, segundo o colaborador permitiram que fosse ressaltado a diferença de largura entre uma passagem mais estreita e o corredor sem estas saliências (Figura 2). Apesar de nem todas as plantas táteis retratadas na bibliografia apresentarem desníveis, serem a representação bidimensional do espaço, nota-se que o acréscimo melhora significativamente a percepção do usuário. Sperling et al. (2015) desenvolveram uma padronização dos elementos que compõem a planta tátil, mencionando cortes em alto e baixo relevo, porém não consideram e mencionam a representação de diferenças de nível.

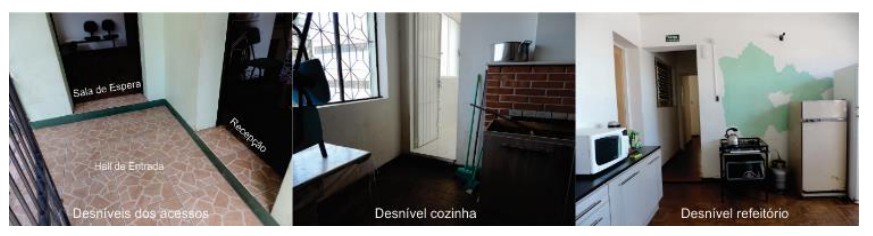

Figura 3: Fotos dos desníveis existentes entre os ambientes na APACE.

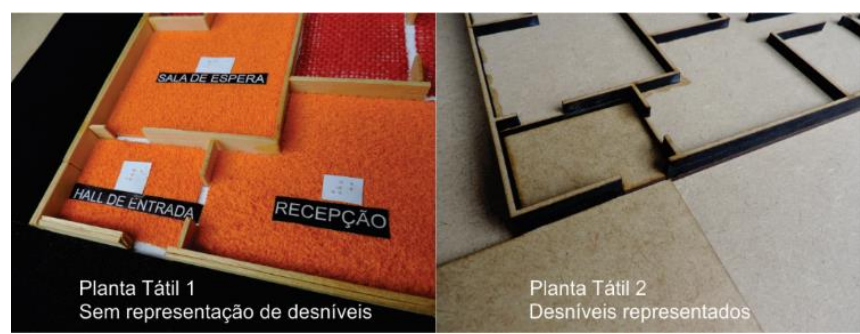

Figura 4: Representação dos desníveis entre hall e sala de espera e recepção na planta tátil 2 e comparativo com a planta tátil 1 sem esta representação.

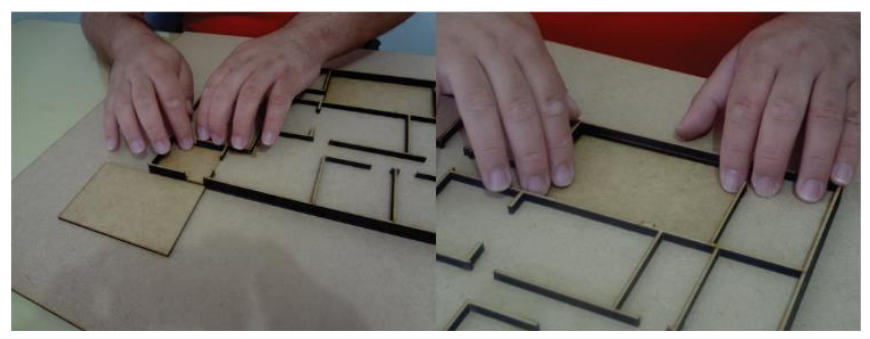


Figura 5: Usuário referência tateando os desníveis da planta tátil 2.

Sperling et al. (2015) realizaram experiência prática com modelos táteis em sala de aula com a ajuda de PDV da turma. A experiência realizada pelos alunos, para uma melhor percepção da condição dos PDVs, foi de privação da visão ao andar pelos corredores da universidade, desta forma foi possível perceber as dificuldades enfrentadas e assim, desenvolver com mais eficácia os modelos táteis. Deste modo, foram testados vários materiais como fios, barbantes, alfinetes, isopor, papéis de várias texturas e gramaturas e materiais orgânicos, dentre outros que estimularam os sentidos dos próprios alunos e do PDV, que era o objetivo inicial. Porém, a variedade de materiais não ajudou para a boa comunicação o que levou a constatação de que é necessário que os materiais sejam escolhidos de forma mais clara e padronizada. A mesma conclusão foi constatada na comparação entre as duas plantas táteis retratadas neste artigo, a planta tátil 1 tinha várias texturas, enquanto que a planta tátil 2 não possuía nenhuma, porém foi considerada melhor e mais clara para a leitura e interpretação dos espaços.

A planta tátil 2 validada pelo usuário referência foi aplicada para 10 (dez) usuários cegos e com baixa visão. A maioria dos PDVs com baixa visão possuem menos de $5 \%$ de visão, se deslocam sozinhos no meio urbano e em ambientes internos, nunca tiveram contato com projeto arquitetônico (nenhum tipo de representação do espaço) e não dominam a leitura em braile.

A posição inicial de leitura da planta foi disposta na posição real do edifício em relação ao acesso, conforme a Figura 6. Os entrevistados que possuíam contato frequente com a instituição (mais de 3 a 4 vezes por semana), sentiam necessidade de virar a planta, como demonstra a Figura 7, para que o acesso ficasse de frente (sentido do acesso), assim demonstravam mais segurança no percurso e também, por mencionarem que a leitura da direita para a esquerda se torna legível e reflete realmente a realidade do lugar, que não possui compartimentos a esquerda do acesso. Um dos entrevistados comentou que virou a planta "pela geografia", outro entrevistado "por onde entra" e outro entrevistado comentou "virada é melhor, pela entrada".

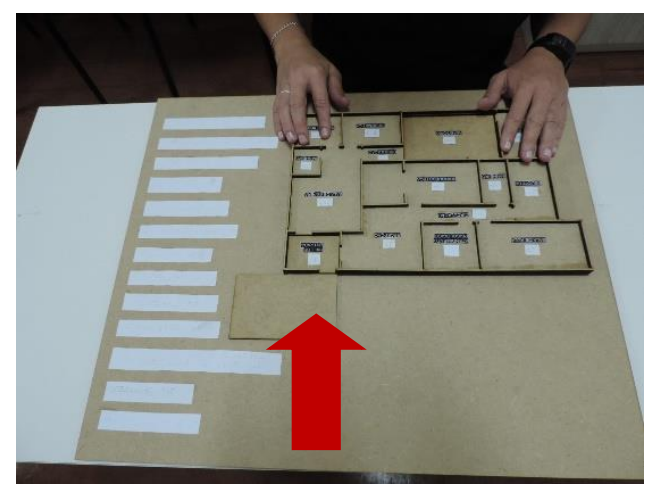

Figura 6: Posição inicial da planta tátil para leitura dos usuários.

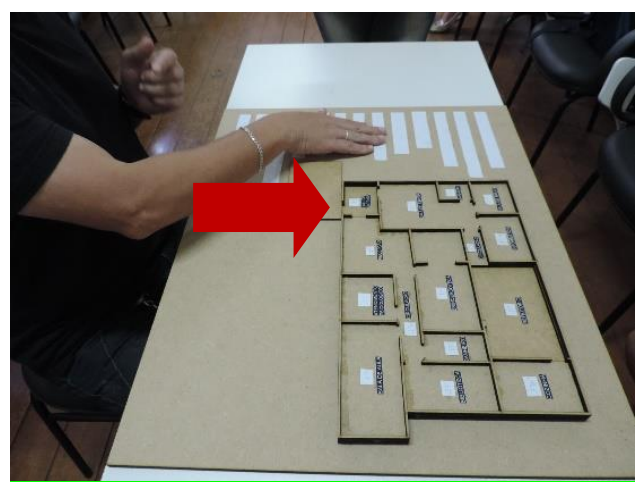

Figura 7: Posição de leitura escolhida pelo usuário.

Pode-se observar que os usuários que frequentam apenas uma vez por semana a instituição não reconheceram todos os compartimentos no percurso realizado, apenas relataram e descreveram os espaços de permanência, que na maioria são a sala de espera, secretaria, sala de braile, refeitório e sala de atendimento psicológico. Estes não mencionaram os detalhes percebidos pelos usuários que utilizam com maior frequência, tais como: o tamanho da sala de espera, e a falta do depósito.

Outra constatação em relação a leitura da planta tátil pelos PDVs é a importância da relação do espaço construído com o ambiente urbano, mencionaram a falta da representação da calçada e do portão de acesso para facilitar o reconhecimento do espaço. Fato que deverá ser revisto pelos pesquisadores em nova planta.

Os entrevistados corroboraram as qualidades da planta tátil 2 mencionada pelo usuário referência, tais como: ser de fácil compreensão, é segura, limpa, os desníveis contribuíram no entendimento dos espaços e o tamanho/escala de representação estava adequado, favorecendo o manuseio e a compreensão do todo.

A grande maioria dos entrevistados gostou da experiência e mencionaram ser possível utilizar o instrumento para poderem opinar sobre o projeto da nova sede da APACE. Foi mencionado como sugestões: a inclusão de mobiliário em 3D na planta (transformaria a planta tátil em uma maquete tátil de ambiente interno), a substituição da escrita em braile de identificação dos ambientes por símbolos tateáveis ou descrição sonora autônoma e a inclusão de texturas diferenciando tipos de pisos.

\section{Considerações Finais}

É importante que os arquitetos e urbanistas e engenheiros comecem a pensar em um método para a elaboração dos espaços e ao mesmo tempo sejam sensíveis para viabilizar a mobilidade com a maior independência possível em espaços pré-existentes, que contribua e promova uma percepção mais apurada do ambiente a ser vivenciado. A legislação, mesmo não garantindo o direito de uma residência acessível, está evidente quanto à implantação de rampas, corrimãos, sinalização, acessos sem barreiras, entre outros (MELLO, 2012). 
Da mesma forma, como é notória a importância das mídias de comunicação para os PDVs (DIAS; ESTANISLAU; BAHIA, 2014). Entre elas as que retratam os espaços e indiquem 0 melhor caminho a percorrer nos ambientes internos e no exterior, garantindo maior segurança e confiabilidade na mobilidade independente.

Bem e Pupo (2015) analisaram estudos de caso onde é usada a prototipagem rápida na confecção de mapas e maquetes táteis, além de concluírem que ainda há poucas publicações sobre 0 assunto, as diferentes técnicas utilizando desta tecnologia possibilitam que a volumetria seja muito mais complexa, aumentando assim as chances de que os objetos produzidos auxiliem ainda mais os PDVs. Nos estudos de caso analisados por Bem e Pupo (2015) foram usados diferentes métodos de prototipagem rápida como por exemplo impressão $3 \mathrm{D}$, sinterização seletiva a laser, combinação de corte a laser e impressão baseada em pó de celulose com representações 2D e 3D e, por fim, produção de mapa com recursos sonoros, constituído por laminado cortado em máquina a laser para demonstrar o caminho que seria realizado pelos usuários e em um segundo momento foi feito uso de impressora 3D baseada em pó para confecção de legendas escritas em braile e demais edificações presentes neste experimento.

Estas possibilidades abrem vários horizontes de exploração, em especial o aprimoramento da representação da planta tátil às maquetes táteis com o uso da impressora 3D, equipamento cada vez mais acessível, viabilizam reproduzir espaços, principalmente os ambientes internos, cada vez mais completos (com mobiliários), detalhados e reais, estimulando as percepções pelo tato dos PDVs.

Por fim, pretendeu-se com esta pesquisa, atender um gargalo social e econômico atual e crescente. Social, do ponto de vista que atualmente a sede da APACE consegue atender apenas $10 \%$ da população Passofundense com algum tipo de deficiência. Com o desenvolvimento de uma nova sede, a associação pretende alcançar 0 atendimento a aproximadamente 1.000 pessoas do município e da região norte do estado do Rio Grande do Sul.

Usar estas representações da configuração real por meio da prototipagem rápida não somente para a compreensão dos PDVs quanto à mobilidade em edificações pré-existentes, mas também em projetos colaborativos que aumente ainda mais a inclusão do PDV na sociedade e sua independência é o próximo objetivo a ser cumprido por esta pesquisa.

A planta tátil 2 da APACE servirá como comparativo para mensurar as dimensões dos ambientes em relação as propostas para a nova sede, que serão apresentadas para os PDVs por meio de planta tátil confeccionada na cortadora a laser, a fim de se construir o projeto colaborativamente.

\section{Referências}

Bem, G. M. de; Pupo, R. T. (2015). Imprimindo o espaço para as pessoas com deficiência visual: uma revisão sistemática. SIGRADI 2015, 148-152.

Caiado, K. R. M. (2002). Cegueira: concepções de aprendizagem e de ensino reveladas em artigos publicados na revista Benjamin Constant. Revista Brasileira de Educação Especial, 8 (2), 223-232.

Dias, R. A.; Estanislau, S. S.; Bahia, I. P. (2014). Maquetes e mapas táteis: diretrizes para projeto, seleção de materiais e técnicas. Ação Ergonômica: Revista da Associação Brasileira de Ergonomia, 9 (1), 44-54.

Espinosa, M.; Ungar, S.; Ochaíta, E.; Blades, M. (1998). Comparing methods for introducing blind and visually impaired people to unifamiliar urban environments. Journal of Environmental Psychology, 18, 277-287.

Faria, A. T.; Elali, G. A. (2012). Promovendo a inclusão: uma experiência de participação de pessoa com deficiência visual no desenvolvimento de um projeto arquitetônico. Ação Ergonômica: Revista da Associação Brasileira de Ergonomia, 7 (2), 61-75.

Heylighen A., Herssens J. (2014). Designerly ways of not knowing. What designers can learn about space from people who are blind, Journal of Urban Design, 19 (3), 317-332.

Instituto Brasileiro de Geografia e Estatística - IBGE (2010). Censo Demográfico 2010 - Características gerais da população, religião e pessoas com deficiência. Retrieved from http://www.ibge.gov.br/home/presidencia/noticias/noticia_imp ressao.php?id_noticia=2170 Deficientes

Lang, J. (ed.) (1974). Designing for Human Behaviour: Architecture and the Behavioral Sciences (Community Development Series). Stroudsburg: Dowden, Hutchinson and Ross.

Mello, R. (2012). Instituto Brasileiro de Desenvolvimento da Arquitetura - IBDA Arquitetura Inclusiva - Uma nova cultura. Retrieved from http://www.forumdaconstrucao.com.br/conteudo.php?a=32\& Cod $=1013$

Milan, L. F. (2008). Maquetes táteis: infográficos tridimensionais para a orientação espacial de deficientes visuais. Revista PARC: Pesquisa em Arquitetura e Construção, 1 (2), 1-26.

Nasar, J. L. (1998). The Evaluative Image of the City. California: Sage Publications.

Organização Mundial da Saúde (Org.) (2011). Informe mundial sobre la discapacidad 2011. Retrieved from www.who.int

Silva, R. R. da; Silva, L F. C. (2013). Avaliação do símbolo de orientação na cartografia Tátil. BCG - Boletim de ciências Geodésicas, 19 (3), 498-509.

Sperling, D. M.; Vandier, I.; Scheeren, R. (2015). Sentir o espaço: projeto com modelos táteis. SIGRADI 2015, 108-112. 


\section{Agradecimentos}

Agradecemos a Fundação Meridional - IMED e Fundação de Amparo à Pesquisa do Estado do Rio Grande do Sul -

FAPERGS pelo financiamento da pesquisa e a Associação

Passofundense de Cegos - APACE pelo apoio ao desenvolvimento da pesquisa. 